\title{
Reflections on Entrepreneurial Learning in Tunisian Universities
}

\author{
Bassem Salhi ${ }^{1} \&$ Salima Taktak ${ }^{1}$ \\ ${ }^{1}$ FSEG Faculty, University of Sfax, Tunisia \\ Correspondence: Salima Taktak, FSEG Faculty, University of Sfax, Tunisia. E-mail: salima.taktak@yahoo.fr
}

$\begin{aligned} & \text { Received: September 4, } 2012 \\ & \text { Accepted: December 4, } 2012 \quad \text { Online Published: January 16, } 2013 \\ & \text { doi:10.5539/jms.v3n1p166 }\end{aligned}$ URL: http://dx.doi.org/10.5539/jms.v3n1p166

\begin{abstract}
Entrepreneurship education helps develop entrepreneurial behavior by stimulating students'entrepreneurial skills. Indeed, students can acquire and implement specific methodologies to create, develop and support new activities. Our study will aim to describe and explain the entrepreneurship education in the Tunisian university. This learning is organized around five key areas: the methodology of entrepreneurship; training seminars; socio-economic development; support entrepreneurship and entrepreneurial values.

By following a hypothetical-deductive and descriptive method, we try to know the influence of exogenous variables that will foster entrepreneurship learning and improve the intent and the entrepreneurial skills of students. In this study, we focus on student populations of 3 years at the university (called LMD in Tunisia) after the program; namely, entrepreneurship awareness and developing a business plan. The choice of this frame is explained by the fact that these students are just a few months away from integrating into the world of work and express a variety of professional career intentions. Our research provides theoretical and practical contributions. In fact, it offers tools to advance the practice of entrepreneurship education at the University of Tunisia, with the aim of promoting the emergence of the entrepreneurial initiatives of students and graduates of the University.
\end{abstract}

Keywords: learning entrepreneurship, teaching methodology, Tunisian universities

\section{Introduction}

Entrepreneurship training should focus on developing entrepreneurial skills and entrepreneurship. To this end, training programs for entrepreneurship may have different objectives, such as the development of the entrepreneurial force students (through education); the staffing of students necessary skills to start a business and manage its growth (by training programs); and the development of entrepreneurial skills in identifying and exploiting opportunities. Drucker (1985) argues that entrepreneurship "is a discipline and, like any discipline, it can be learned." Also according to Politis (2006), entrepreneurship can be acquired, or even taught.

It is in this sense that Fayolle (2000) and Drink, et. al. (2008) explored the links between education and entrepreneurship and strategic learning styles to follow to lead to economic performance and the reduction of unemployment rate. The teaching of entrepreneurship is a critical tool for developing entrepreneurial behaviors of students. Several authors agree in recognizing that there is no ideal content and the knowledge, skills, and attitudes vary according to the needs of student learning. For some, these needs can develop in a business context and not in a school (Schied-Bienfait, 1999). Other authors advocate another view: that entrepreneurship learning is only effective when started within the university setting. Our study will aim to describe and explain the determinants of entrepreneurship learning in universities that will focus on five areas: The methodology of entrepreneurship; training seminars; the socio- economic, entrepreneurial coaching and entrepreneurial values. The central question of our research is to understand the effect of explanatory variables on the learning model of entrepreneurship at a university that is triggering the entrepreneurial spirit

We thus have, according to a hypothetical deductive and descriptive, to know the positive influence of exogenous variables that will foster entrepreneurship learning and improve the intent and the entrepreneurial skills of students.

We are interested in student populations of 3 years at the university (called LMD in Tunisia) after the program namely entrepreneurship awareness and developing a business plan. The choice of this frame is explained by the fact that these students are just a few months away from integration into the world of work and expressing a variety of professional career intentions. 


\section{Entrepreneurship Learning in Tunisian Universities}

The literature on entrepreneurship education shows the importance of this particular academic phenomenon. In fact, several authors state that it will allow educational institutions to create ways to positively influence the development of entrepreneurship among young people. Alberti et. al (2004) states that the evolution of studies concerning the teaching of entrepreneurship is the main cause of poverty and lack of research paradigms, models and theories accepted and shared learning of entrepreneurship. Indeed, there is no clear agreement on the nature and objectives of entrepreneurship learning.

The teaching of entrepreneurship in the university aims to demonstrate the ability of an entrepreneurial education system to help emanate an entrepreneurial spirit among students and have an impact on their business intentions.

In Tunisia, entrepreneurship consists of three consecutive games and progressive. The first part corresponds to the second program year of applied or fundamental that processes the training module "entrepreneurial culture". It takes place throughout the first half of the academic year for a goal to encourage students to become tomorrow's entrepreneurs. The interest in entrepreneurship education is not limited to increasing the number of new businesses. In fact, this course allows the student awareness of key concepts of entrepreneurs (behaviors, motivations and actions). During the second semester of that year, the teacher primarily stimulates entrepreneurial intention and simulates stages of business creation as a source of ideas, analysis of opportunities, planning, decision, organization and control. Finally, in the first half of the third year the program is structured around the accompaniment of the development of a business plan. In fact, the current business plan has become an indispensable tool in business creation. In the second semester, students (third year level) are invited to prepare a training report, in an environment that operates in an industry similar to their individual specialty. They can also opt to develop a business plan, after creating an innovative idea, feasible and bankable by structured finance. In this case students will benefit from support provided by a scholar and a professional coach.

\section{The Research Context and Description of Variables}

This theme is to describe and justify our empirical methodology. We begin the presentation by the justifications of the hypothetical-deductive logic and quantitative consolidated by a qualitative survey.

\subsection{The Exploratory Phase}

The exploratory phase is an important step, because the definition and translation of concepts into items depends, in part, on the quality of the measurement. This phase is broken down into four stages: the specification of the built environment, generating a sample of items, data collection and purification of the measuring instrument.

\subsubsection{Specification of the Built}

Initially, it involves identifying a comprehensive, all built and variables useful for understanding the problem being studied. In a second step, it is retained for each issue of an explanatory variable definition, or to propose such a literature does not provide one.

\subsubsection{Data Collection}

At this stage of the method, we stopped the mode of administration of the questionnaire and the sample size. This is a questionnaire divided into seven groups of questions to endogenous, five exogenous variables and socio-demographic questions. Measuring instruments reflect our assumed variables, circumscribed by questions of different natures, in order to confirm or overturn them. Our approach is based on hypothetical-deductive built a set of articulated within a model which would reproduce a valid interpretation of entrepreneurial learning students.

The questionnaire was thus composed of questions divided into seven main parts:

- Part 1: demographic questions.

- Part 2: questions about entrepreneurship learning.

- Part 3: issues concerned with teaching methodology.

- Part 4: questions on training seminars.

- Part 5: questions about the socio-economic environment.

- Part 6: guidance on entrepreneurial issues.

- Part 7: issues concerned with entrepreneurial values.

Our questions are those that have answers based on five degrees (Likert Scale). We should mention that the questionnaire follows a pre-test. Indeed, to increase the validity of the questionnaire about twenty people have 
responded to an initial version of this questionnaire in addition to being interviewed. Changes were made to the questionnaire after this pre-test which, according to Cook and Mark (1982) is the best way to increase the link between a built and operational model. Data collection was therefore carried out through a questionnaire that was developed for the purpose of this research.

- Population: Students in the third year (BMD) in all disciplines who attended the course in entrepreneurship.

- Sample size: 120 students. (University of Sfax)

- Temporal context: The second half (2011).

We chose the students who followed in the first half during the entrepreneurial culture in the second half, the current business development and training at the end of producing a business plan.

\subsection{The Description of the Research Variables}

The statistical analysis techniques including PCA (Principal Component Analysis), partly condition the sample size. According to scientific rigor one wants to impose on its results.

\subsubsection{Definition of the Dependent Variable}

In this study, we focus on the entrepreneurial learning of the student during his university career. Learning is a process of acquiring new knowledge or behavior, as a result of interactions with the environment. In a school context, learning refers to activities that enable a person to acquire or develop knowledge, or develop skills. It is through a set of activities included in the courses and training for entrepreneurship organized by the University with other institutions, students can engage in learning and thus gain knowledge and develop attitudes and entrepreneurial behaviors.

\subsubsection{Definition of Independent Variables}

\subsubsection{The Teaching Methodology}

The importance of the method in the learning process is critical. Carrier (2001) states that the teaching of entrepreneurship at the universities is rather a matter of method not content. Currently, a number of American and European universities have adopted a more business-based teaching of entrepreneurship. This method suggests the passage of "teaching for" to "teaching about" in the context of learning by experience that affects the emotional and cognitive education (Gibb, 1998). The introduction of entrepreneurship learning at an early stage of education is vital here, because young minds are most receptive to influences and ideas. Ideally, this is when the seeds of the spirit business should be sown. Very often when we talk about the specifics of entrepreneurship and how we could teach it, we talk about active teaching methods, experiential approaches. But beyond the words and ways, few teachers in the field are able to justify their choice theoretically and empirically. It is in this spirit Brent Ruben (1999) states that the acquisition of knowledge and skill lies not in knowing but in the ability to use knowledge and the ability to transform knowledge in behavior. Therefore, we formulate our first hypothesis:

H1: The teaching methodology positively influences learning in college.

\subsubsection{The Training Seminars}

The training seminars of entrepreneurship correspond to the construction and development of a process completed more than one result symbolized by the creation of businesses.

According to P. Kearnay (2009), the methodology of educating students is a process of entrepreneurial learning attitudes, which revolves around three axes: experimentation, reflexivity and cooperation.

Today the formation of entrepreneurship can define a model of learning at the university and especially entrepreneurial process as a catalyst for entrepreneurship. Schmitt (1992) argues that entrepreneurship education is primarily in the construction and development of a process completed by starting a business. So that we conduct to ask the following hypothesis:

$\mathrm{H} 2$ : The training seminars positively influence the entrepreneurship learning in college.

\subsubsection{The Socio-Economic}

The Contractor must "learn to cope" (Borges et al. 2005). In fact, some individuals possess a greater potential for success in entrepreneurial activity because of the cultures of their familial environment or the environment in which they operate. Deakins et al (2002), Borges et al. (2005) show that the need to learn is generated by the need to adapt to environmental changes and allows the contractor to be proactive. 
The social-economic environment plays a decisive role not only in the process of implementation, but also psychologically in the sense that it induces effects on choice behavior of the young entrepreneur. Therefore, we formulate our third hypothesis:

H3: The social-economic environment positively influences entrepreneurship learning.

\subsubsection{Entrepreneurial Coaching}

Several researchers show that support is essential for any entrepreneurial activity. In fact, Honig (2006) says the United States, $78 \%$ of the top universities offer courses specifically dedicated to assembling business plans. The same author defines a business plan as a document describing the current state and desired future of an organization. The process of building the business plan seems essential for the realization of a business (Barringer and Gresock, 2008, Kraus et al. 2006). It promotes the survival of businesses created (Castrogiovanni, 1996) and substantially increased the likelihood of successfully launching them (Liao and Gartner, 2008).

Currently, the business plan has become an indispensable tool for business creation. All financing structures encourage project sponsors to submit their business plan to grant credits.

According to Berger (2003) coaching can play an effective role as "catalyst" of the entrepreneurial process. So, from these overlapping previous studies, we formulate our research hypothesis:

H4: The support in the realization of a business plan positively influences entrepreneurship learning at university.

\subsubsection{Entrepreneurial Values}

Entrepreneurship is both a science and an art; it is a very complex task as indicated in the work of Anderson and Jack (1999). Indeed, to ensure the success of the entrepreneurial process, the contractor must have different types of skills. In addition to technical and business skills (including the purpose for an entrepreneur is creating a business plan); He must have managerial skills, social and personal.

Chandler and Hanks (1994), Baum (1995) concerned with the impact of entrepreneurial values on performance and value creation. Based on this literature review, we formulate our last hypothesis:

H5: The entrepreneurial values positively influence entrepreneurship learning at university.

\section{The Choice of Method of Data Analysis}

We use SPSS for statistical treatment of all quantitative data collected. Excel provides results when performing a multiple regression (output ToolPack Data Analysis). According to Evrad et al. (2003), the choice of the explanatory method suitable for statistical processing of data depends on how the dependent variable and the explanatory variables were measured.

\subsection{The Dimensionality}

Dimensionality based on factor analysis. The potential of the principal component analysis (PCA) for the purification and validation of scales made it a descriptive method most used (Roussel, 1998). This method must be established prior to the calculation of reliability.

\subsection{Reliability}

The reliability (internal consistency also called "Internal Consistency Reliability") provides confirmation of the homogeneity of a scale which can be built one-dimensional or multidimensional. Reliability is a necessary but not sufficient for the validity (Evrard et al (1997); Igalens and Roussel (1998)). It aims to reduce the random error. Internal consistency informs us, through Cronbach's alpha, of the correlation of each item on a scale with at least one other item of it. Thus, these items measure precisely and solely the built analyzed and thus share a common notion. The coefficient alpha estimates the total score variance common factors specific scale items tested.

\subsection{The Correlation}

The simple correlation is a specification of the relationship between two categories of variables: a variable and a dependent variable. The linear correlation coefficient ( $\mathrm{r}$ between -1 and +1$)$ developed by Pearson is the most widely used indicator to measure the intensity of entrepreneurial learning.

\subsection{The Simple Regression Analysis}

This analysis is an explanatory and predictive methods most used. Frequently based on the problem of the linear fit, it permits verification of the causal (explanatory variable) and effect (dependent variable) between two quantitative variables (metric) which has been postulated the existence and meaning in the corresponding hypothesis (Evard et al, 1997). The simple linear regression analysis to identify the coefficients of the equation of the line that minimize the dispersion I observed between ordered and ordered adjusted. 
Using this equation, the interpretation of the results of a regression occurs at three levels (Evard et al, 1997). The intensity of the relationship between the two variables is calculated using the linear correlation coefficient (R). It is the same for the significance of the link and the goodness of fit of the model in which indicators are the linear coefficient of determination (R2) and the F test of Fisher-Snedecor. Finally, the regression allows examination "residues" in ruling on the accuracy of the model; that is to say, the difference between the values predicted by the model and those actually observed.

\section{Tests and Analyzes of Condensation Scales}

\subsection{The Teaching Methodology}

We designed a multi-scale table to measure this variable. To test its dimensionality, we conducted a factor analysis reported in the table below. The resolution process is used to identify the factorial axes, calculate the variance associated with them and the contributions of each factor item.

This factor accounts for $55,711 \%$ of the explained variance of information, slightly higher than the criterion of $50 \%$ contribution. The scale thus formed is one-dimensional and statements that compose it have a coefficient of internal consistency (Cronbach's alpha) of 0.670 .

Table 1. Factor analysis of the variable of teaching methodology

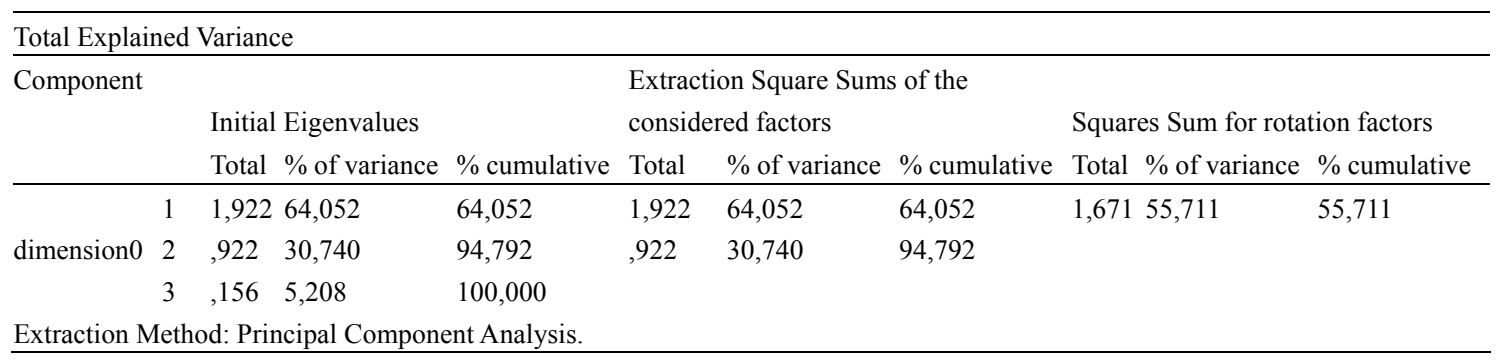

Table 2. Cronbach's alpha for the variable of teaching methodology

\begin{tabular}{lll}
\hline & Reliabilit Statistics \\
\hline & Cronbach's alpha based on standardized \\
Cronbach's alpha & elements & Element Number \\
, 670 &, 698 & 3 \\
\hline
\end{tabular}

\subsection{The Training Seminars}

We designed a multi-scale, multiple item tables to measure this variable. To test its dimensionality, we conducted a factor analysis reported in the table below. The resolution process is used to identify the factorial axes, calculate the variance associated with them and the contributions of each factor item.

PCA indicates that the variable "training seminars" thus formed is one-dimensional. In addition, $60,976 \%$ of the information collected is represented by the only factor containing these items.

Table 3. Factor analysis of the variable training seminars

\begin{tabular}{|c|c|c|c|c|c|c|c|}
\hline \multicolumn{8}{|c|}{ Totale Explained Variance } \\
\hline \multirow{2}{*}{\multicolumn{5}{|c|}{ Initial Eigenvalues }} & \multirow{2}{*}{\multicolumn{3}{|c|}{$\begin{array}{l}\text { Extraction Square Sums of the considered } \\
\text { factors }\end{array}$}} \\
\hline & & & & & & & \\
\hline & & Total & $\%$ of variance & $\%$ cumulative & Total & $\%$ of variance & $\%$ cumulative \\
\hline \multirow{4}{*}{ dimension 0} & 1 & 2,439 & 60,976 & 60,976 & \multirow[t]{4}{*}{2,439} & \multirow[t]{4}{*}{60,976} & \multirow[t]{4}{*}{60,976} \\
\hline & 2 & 1,146 & 28,652 & 89,628 & & & \\
\hline & 3 & ,415 & 10,372 & 100,000 & & & \\
\hline & 4 & $-6,330 \mathrm{E}-16$ & $-1,582 \mathrm{E}-14$ & 100,000 & & & \\
\hline \multicolumn{8}{|c|}{ Extraction Method: Principal Component Analysis. } \\
\hline
\end{tabular}


Reliability is a necessary condition of homogeneity; we proceeded to test internal consistency to deepen the results of the CPA. This calculation, on the one hand, shows the correlation of each item with a global scale. On the other hand, the alpha is calculated within each time an item of the scale. The overall alpha is equal to 0.759 .

Table 4. Cronbach's alpha of the variable training seminar

\begin{tabular}{ll}
\hline Statistiques de fiabilité & \\
\hline Cronbach's alpha & Element Number \\
, 759 & 4 \\
\hline
\end{tabular}

\subsection{The Socio-Economic}

PCA indicates that the variable "socioeconomic environment" thus formed is one-dimensional. This factor accounts for $59,067 \%$ of the explained variance of the information and made statements that compose it have a coefficient of internal consistency (Cronbach's alpha) of 0,760 satisfactory.

Table 5. Factor analysis of the socioeconomic environment variable

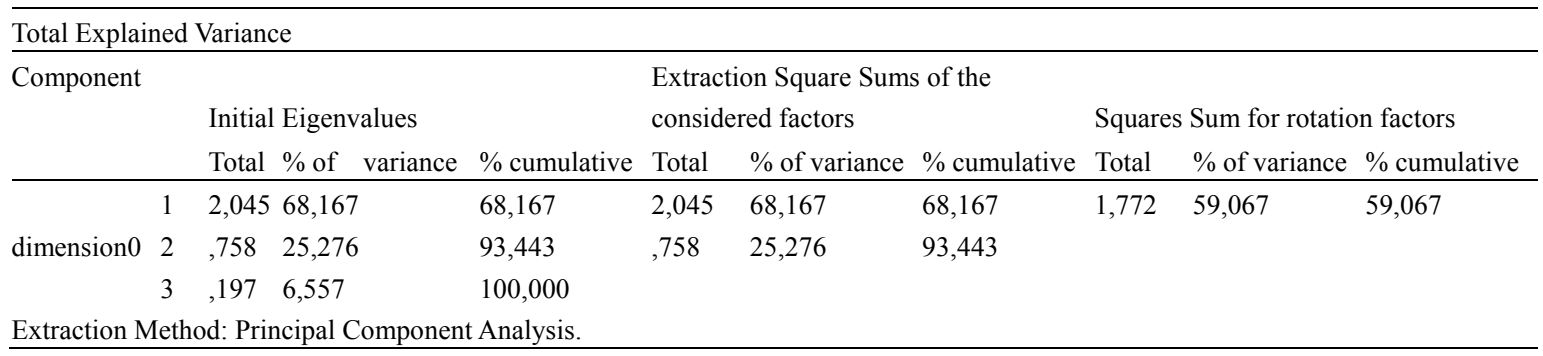

Table 6. Cronbach's alpha of the variable socio-economic environment

\begin{tabular}{lll}
\hline & Reliabilit Statistics \\
\hline & Cronbach's alpha based on standardized \\
Cronbach's alpha & elements & Number of elements \\
,760 &, 754 & 3 \\
\hline
\end{tabular}

\subsection{Entrepreneurial Coaching}

The variable "entrepreneurial coaching" contains 7 items. Factor analysis on the sample demonstrates the uni-dimensionality of the construct. The total variance of the point cloud, concentrated on a single axis, returns a good value of the total information $(67,166)$.

Examine the reliability to rule on the consistency of this scale (table below). The calculation reveals an alpha coefficient above the threshold $(0,691)$.

Table 7. Factor analysis of the variable support entrepreneurial

\begin{tabular}{|c|c|c|c|c|c|c|c|c|c|}
\hline \multicolumn{10}{|c|}{ Total Explained Variance } \\
\hline \multirow{2}{*}{\multicolumn{5}{|c|}{ Component }} & \multirow{2}{*}{\multicolumn{3}{|c|}{$\begin{array}{l}\text { Extraction squares Sums of the } \\
\text { considered factors }\end{array}$}} & \multirow{2}{*}{\multicolumn{2}{|c|}{ Squares Sum for rotation factors }} \\
\hline & & & & & & & & & \\
\hline & & \multicolumn{3}{|c|}{ Total $\%$ of the variance $\%$ cumulative } & Total & $\%$ of the & variance $\%$ cumulative & \multirow{2}{*}{$\frac{\text { Total } \% \text { of the variance }}{4,70267,166}$} & \multirow{2}{*}{$\frac{\% \text { cumulative }}{67,166}$} \\
\hline \multirow{7}{*}{ dimension 0} & 1 & 5,085 & 72,647 & 72,647 & 5,085 & 72,647 & 72,647 & & \\
\hline & 2 & 890 & 12,714 & 85,361 &, 890 & 12,714 & 85,361 & & \\
\hline & 3 & 675 & 9,641 & 95,002 & & & & & \\
\hline & 4 & ,229 & 3,270 & 98,272 & & & & & \\
\hline & 5 &, 121 & 1,728 & 100,000 & & & & & \\
\hline & 6 & $1,611 \mathrm{E}$ & 5 2,301E-14 & 100,000 & & & & & \\
\hline & 7 & $1,203 \mathrm{H}$ & 5 1,718E-14 & 100,000 & & & & & \\
\hline
\end{tabular}


Table 8. Cronbach's alpha of the variable support entrepreneurial

\begin{tabular}{lll}
\hline Statistiques de fiabilité & & \\
& Cronbach's alpha based on standardized & \\
Cronbach's alpha & elements & Element Number \\
,691 &, 732 & 7 \\
\hline
\end{tabular}

\subsection{Entrepreneurial Values}

This factor accounts for $56,757 \%$ of the explained variance of information made in specific lessons to entrepreneurship, and statements that compose it have a coefficient of internal consistency (Cronbach's alpha) of 0.567 satisfactory.

Table 9. Factor analysis of the variable business values

\begin{tabular}{|c|c|c|c|c|c|c|c|}
\hline \multirow[t]{2}{*}{ Component } & & \multicolumn{3}{|c|}{ Initial Eigenvalues } & \multicolumn{3}{|c|}{$\begin{array}{l}\text { Extraction squares Sums of the } \\
\text { considered factors }\end{array}$} \\
\hline & & \multirow{2}{*}{$\frac{\text { Total }}{2,838}$} & \multicolumn{2}{|c|}{$\%$ of the variance $\%$ cumulative } & \multirow{2}{*}{$\begin{array}{c}\text { Total } \\
2,838\end{array}$} & \multicolumn{2}{|c|}{$\%$ of the variance $\%$ cumulative } \\
\hline \multirow{5}{*}{ dimension 0} & 1 & & 56,757 & 56,757 & & 56,757 & 56,757 \\
\hline & 2 & 1,163 & 23,260 & 80,017 & & & \\
\hline & 3 &, 558 & 11,159 & 91,176 & & & \\
\hline & 4 & ,329 & 6,584 & 97,760 & & & \\
\hline & 5 &, 112 & 2,240 & 100,000 & & & \\
\hline \multicolumn{8}{|c|}{ Extraction Method: Principal Component Analysis. } \\
\hline
\end{tabular}

Table 10. Cronbach's alpha values of the variable entrepreneurial

\begin{tabular}{ll}
\hline Statistiques de fiabilité & \\
\hline Cronbach's alpha & Element Number \\
, 567 & 5 \\
\hline
\end{tabular}

\section{Testing and Validation of Analytical Assumptions}

Accepting a hypothesis implies that the data collected during an investigation is compatible with it. "It would be fairer to say that the hypothesis is 'not rejected' rather than 'accepted' because there is no evidence that other assumptions would not be equally acceptable" (Evrard et al, 1997). This interpretative precaution is taken into account, we will do statistical analyzes to confirm or refute the hypotheses one by one.

\subsection{Results of Regression Analyzes Based on the Factor "Entrepreneurial Learning"}

The procedure for variable selection is based on the method of "backward elimination". The detailed results on the steps of removing the insignificant variables are presented below.

\subsubsection{The Influence of the Teaching Methodology}

The influence of the teaching methodology on learning entrepreneurship is verified through the technique of-way ANOVA. This technique is particularly suited to the case of a qualitative explanatory variable and a variable to be explained quantitatively.

The calculation is done by transforming the two variations (intergroup and intragroup) at a ratio of variance that is obtained by dividing each of them by the number of degrees of freedom appropriate. We obtain a factor $F$ Fisher-Snedecor whose statistical properties are known. We compare the calculated value of $F$ to its critical value, a fixed threshold $\alpha$ and the number of degrees of freedom corresponding.

For the reference sample, the Fisher-Snedecor table gives for $\alpha=0.05$ for 1 and 176 degrees of freedom, a value of 3.84. The one we have calculated (1555.753) it is much higher (Table 11).

We therefore conclude that the data collected can rule in favor of an influence highly significant $(\mathrm{F}=1555,753$ and $\mathrm{sig}=0.000$ ) of the teaching methodology on learning entrepreneurship. The teaching methodology positively influences learning in college. Indeed, the teaching of entrepreneurship in universities is a matter of method rather than content. Therefore, the hypothesis $\mathrm{H} 1$ is not rejected within the reference sample. 
Table 11. Explanatory analysis of a simple regression of "teaching methodology" vs. "learning entrepreneurship"

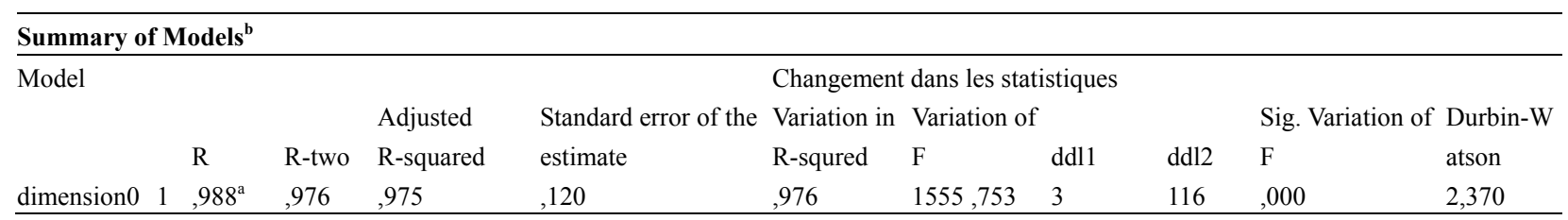

a. Predictors: (constant), teaching methodology

b. Dependent Variable: entrepreneurship learning

\begin{tabular}{lllllll}
\hline ANOVA $^{\mathbf{b}}$ & \multicolumn{1}{l}{} & & & \\
\hline Model & & Sum of squres & ddl & Mean squares & D & Sig. \\
1 & Regression & 66,928 & 3 & 22,309 & 1555,753 &, $000^{\text {a }}$ \\
& Residue & 1,663 & 116 &, 014 & & \\
& Total & 68,592 & 119 & & & \\
\hline
\end{tabular}

a. Predictors: (constant), teaching methodology

b. Dependent Variable: entrepreneurship learning

\subsubsection{The Influence of Training Seminars}

The results of our study, in the Tunisian University, show a good correlation between training seminar and learning about entrepreneurship (Table 12). The effect of this relationship is estimated at $72.5 \%$. The quality of adjustment of the relationship obtained by simple regression is acceptable, the correlation is more significant. Indeed, the observed value of the coefficient $F(42,746$ for a sig. $=000)$ is much higher than the critical value $(3.84$ at $\alpha=0.05$ level for 1 and 148 degrees of freedom).

Therefore, there is a significant dependence between the fact of seminar training and learning about entrepreneurship. The more students are seeking information and training to better conceptualize some aspects of their ideas or projects, the better their learning entrepreneurship. So, we can say that the training seminars correspond to the construction and development of entrepreneurship. Thus, on the basis of the simple regression test, hypothesis 2 is not rejected with respect to the target population.

Table 12. Explanatory analysis of a simple regression of the "training seminar" vs. "learning of entrepreneurship"

\begin{tabular}{|c|c|c|c|c|c|c|c|c|c|c|}
\hline \multicolumn{11}{|c|}{ Récapitulatif des modèles ${ }^{b}$} \\
\hline \multirow[t]{3}{*}{ Model } & & & & & Changement & dans les stati & istique & & & \\
\hline & & & R-square & Standard Error of & Variation in & Variation of & & & Sig. Variation & \\
\hline & $\mathrm{R}$ & R-two & adjusted & the estimate & R-squared & $\mathrm{F}$ & ddl1 & dd12 & of $\mathrm{F}$ & Durbin-Watson \\
\hline 1 &, $725^{\mathrm{a}}$ &, 525 &, 513 & ,336 &, 525 & 42,746 & 3 & 116 &, 000 & 2,075 \\
\hline
\end{tabular}

a. Predictors: (constant), training seminar

b. Dependent Variable: entrepreneurship learning

\begin{tabular}{lllllll}
\hline ANOVA $^{\mathbf{b}}$ & \multicolumn{1}{l}{} & & & & \\
\hline Model & & Sum of squres & ddl & Mean squares & D & Sig. \\
1 & Regression & 14,487 & 4 & 4,829 & 42,746 &, $000^{\text {a }}$ \\
& Residue & 13,105 & 116 &, 113 & & \\
& Total & 27,592 & 120 & & & \\
\hline
\end{tabular}

a. Predictors: (constant), training seminar

b. Dependent Variable: entrepreneurship learning 


\subsubsection{The Influence of the Socio-Economic}

Table 13. Explanatory analysis of a simple regression of the "socioeconomic environment" vs. "learning of entrepreneurship"

\begin{tabular}{|c|c|c|c|c|c|c|c|c|c|c|}
\hline \multicolumn{11}{|c|}{$\underline{\text { Summary of models }}$} \\
\hline \multirow[t]{2}{*}{ Model } & \multicolumn{10}{|c|}{ Changement dans les statistiques } \\
\hline & $\mathrm{R}$ & R-two & $\begin{array}{l}\text { R-square } \\
\text { adjusted }\end{array}$ & $\begin{array}{l}\text { Standard Error of } \\
\text { the estimate }\end{array}$ & $\begin{array}{l}\text { Variation in } \\
\text { R-squared }\end{array}$ & $\begin{array}{l}\text { Variation of } \\
\mathrm{F}\end{array}$ & ddl1 & ddl2 & $\begin{array}{l}\text { Sig. Variation of } \\
\text { F }\end{array}$ & Durbin-Watson \\
\hline Dimension 01 &, $952^{\mathrm{a}}$ &, 906 & ,901 &, 254 & ,906 & 61,210 & 6 & 113 &, 000 & 2,224 \\
\hline
\end{tabular}

a. Predictors: (constant), socio-economic environment

b. Dependent variable: entrepreneurship learning

\begin{tabular}{lllllll}
\hline ANOVA $^{\mathbf{b}}$ & & & & & \\
\hline Model & & Sum of squres & ddl & Mean squares & D & Sig. \\
1 & regression & 31,022 & 3 & 15,511 & 61,210 &, $000^{\mathbf{a}}$ \\
& Residue & 60,311 & 116 &, 588 & & \\
& Total & 91,333 & 119 & & & \\
\hline
\end{tabular}

a. Predictors: (constant), socio-economic environment

b. Dependent variable: entrepreneurship learning

Based on the picture presented above, we find a satisfactory correlation between the social-economic and entrepreneurial learning. The effect of this relationship is estimated at $95.2 \%$. The share of the perceived desirability factor is explained by $90.6 \%$. The quality of the relationship obtained by simple regression is acceptable and the link is significant. Indeed, the observed value of the coefficient $F(61,210$ for a sig. $=000)$ far exceeds the critical value (3.84, the threshold $\alpha=0.05$ for 1 and 148 degrees of freedom).

The socio-economic environment plays a decisive role in the learning process, especially on the psychological, in that it induces effects on choice behavior of young entrepreneur. Thus, based on the test of simple regression, hypothesis 3 is not rejected within the reference sample.

\subsubsection{The Influence of Entrepreneurial Support}

Table 14. Explanatory analysis of a simple regression of "entrepreneurial coaching" from the "entrepreneurial learning"

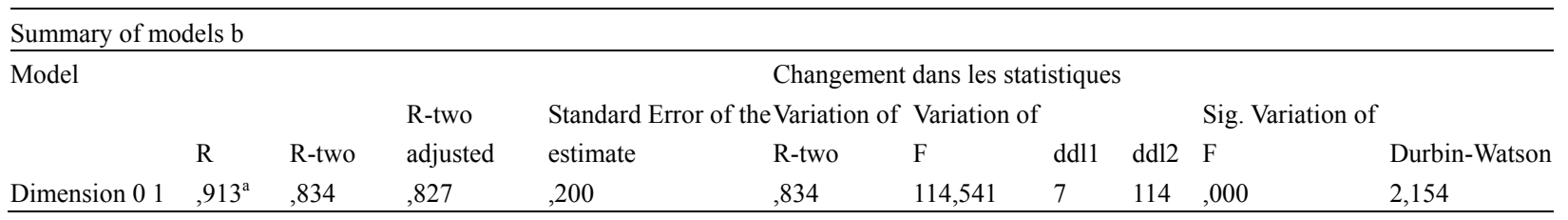

a. Predictors: (constant), supporting entrepreneurial

\begin{tabular}{lllllll}
\hline \multicolumn{1}{l}{ ANOVA $^{\mathbf{b}}$} & \multicolumn{1}{l}{} \\
\hline \multicolumn{2}{l}{ Model } & Sum of squres & ddl & Mean squares & D & Sig. \\
1 & regression & 23,011 & 7 & 4,602 & 114,541 &, $000^{\mathrm{a}}$ \\
& Residue & 4,581 & 114 &, 040 & & \\
& Total & 27,592 & 121 & & & \\
\hline
\end{tabular}

a. Predictors: (constant), entrepreneurial support

b. Dependent variable: entrepreneurship learning 
The result, presented in the tables above, shows a satisfactory correlation between entrepreneurial coaching and entrepreneurial learning. The effect of this relationship is estimated at $91.3 \%$.

The quality of fit of the relationship obtained by simple regression is acceptable and the link is significant. Indeed, the observed value of the coefficient F (114 541 for a sig. $=000)$ far exceeds the critical value $(3.84$, the threshold $\alpha=0.05$ for 1 and 148 degrees of freedom).

So, there is a significant dependence between having entrepreneurial coaching and learning entrepreneurship. The more students are together in developing the business plan to better formalize certain aspects of their ideas or projects, the better their entrepreneurship learning. Thus, based on the simple regression test, hypothesis 4 is not rejected within the reference population.

6.1.5 The Influence of Entrepreneurial Values

Table 15. Explanatory analysis of a simple regression of "entrepreneurial values" vs. "learning of entrepreneurship"

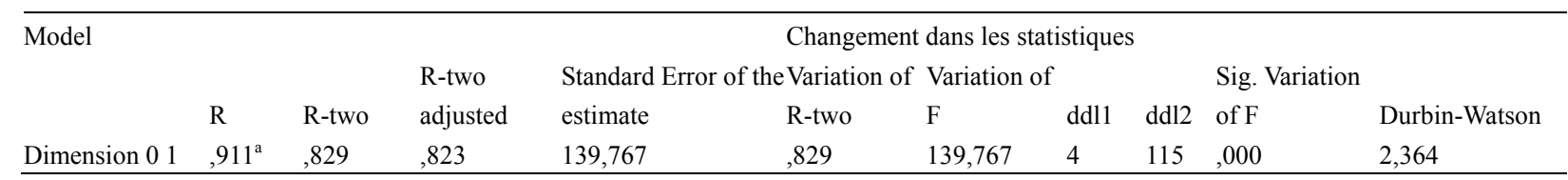

a. Predictors: (constant), entrepreneurial values

b. Dependent variable: entrepreneurship learning

\begin{tabular}{lllllll}
\hline ANOVA $^{\mathbf{b}}$ & \multicolumn{1}{l}{} & \\
\hline Model & & Sum of squres & ddl & Mean squares & D & Sig. \\
1 & regression & 56,890 & 5 & 14,222 & 139,767 &, $000^{\text {a }}$ \\
& Residue & 11,702 & 115 &, 102 & & \\
& Total & 68,592 & 120 & & & \\
\hline
\end{tabular}

a. Predictors: (constant), entrepreneurial values

b. Dependent variable: entrepreneurship learning

In this empirical study, we find that there is a satisfactory correlation between the values of entrepreneurship and entrepreneurial learning. The effect of this relationship is estimated at $91.1 \%$. The share of the perceived desirability factor is explained by $82.9 \%$.

The goodness of fit of the relationship obtained by simple regression is acceptable and the link is significant. Indeed, the observed value of the coefficient F (139.767 for a sig. $=000)$ far exceeds the critical value $(3.84$, the threshold $\alpha=0.05$ for 1 and 148 degrees of freedom).

The effect of entrepreneurial values on entrepreneurship learning is so crucial; they have a positive impact on performance and value creation. The hypothesis $\mathrm{H} 5$ is not rejected within the reference sample.

\subsection{An Explanatory Model of Entrepreneurial Learning Tested in the Context of Entrepreneurship Education}

Through out this quantitative analysis, we showed that the five assumptions are validated. Taking into account the results of this study, it is important to emphasize the fundamental contribution of the teaching methodology in student learning. Coaching has given students the attitude necessary for the acquisition and development of many entrepreneurial qualities. This entrepreneurial learning is developed by training seminars in business creation in a social-economic environment conducive to developing students' entrepreneurial values.

The exogenous variables of our model positively affect entrepreneurial learning in students. Thus we can present the validation of assumptions in the table below: 
Table 16. The validation of assumptions

\begin{tabular}{llll}
\hline The dependent variable & The explanatory variables & Hypotheses & Validation \\
\hline \multirow{4}{*}{$\begin{array}{l}\text { Learning entrepreneurship at } \\
\text { the university }\end{array}$} & Teaching Methodology & H1 & Confirmed \\
& Training seminars & H2 & Confirmed \\
& Socio-economic environment & H3 & Confirmed \\
& Entrepreneurial Coaching & H4 & Confirmed \\
& Entrepreneurial values & H5 & Confirmed \\
\hline
\end{tabular}

Entrepreneurship education helps develop entrepreneurial behavior by stimulating their entrepreneurial skills to acquire and implement methodologies and specific tools to create, develop and support new activities. Universities are repositories of knowledge on future technology trends, economic and social gateways to global information and sources of expertise in the regional analysis. They bring to their area of knowledge for planning its future and support the regional infrastructure.

\section{Conclusion}

Our research provides theoretical and practical contributions. In fact, it offers tools to advance the practice of entrepreneurship education at the University of Tunisia, with the aim of promoting the emergence of the entrepreneurial initiatives of students and graduates of higher education.

Entrepreneurial learning is a new theme that allows the student to acquire and to develop entrepreneurial skills. It has importance in both academic and professional life. Indeed, the evolution of regular research university to an entrepreneurial university system is a topical phenomenon. Universities become drivers of innovation, knowledge vigils on future technology trends, economic and social gateways to global information, and sources of expertise in the regional analysis.

In this research, based on a robust literature review, we construct a model of entrepreneurial learning that focuses on five areas, namely: The methodology of teaching, training seminars, the environment socio-economic development, support entrepreneurship and entrepreneurial values.

We note in our study that there is a good balance between theory and practice on two levels. First, the program where the activity is action-oriented based on experience and projects. It aims to improve students' ability to work in teams, create and use networks, solve problems and identify opportunities. Students are actively involved in the learning process and responsible for their own education. Second, the program of the activity is suited to the learning environment of students and their specific areas of study.

Furthermore, we show in this research that there is no dialogue or cooperation between different departments of government support policies and measures in the field of entrepreneurship education. Thus, there is a lack of cooperation between stakeholders and universities at the regional level. In fact, institutional cooperation between the formal education system and the labor market is weak.

In our empirical study we find some difficulties - mainly in measuring the effects of entrepreneurial training. Indeed, we lack experience in measurement and evaluation of results, since the university environment is isolated and does not maintain relationships with local contractors.

Entrepreneurship is considered a course leading to a note rather than as a way of thinking or a permanent attitude. The time spent in class is often insufficient, and there is increasing competition with other activities. In fact, learning is done by managing a specific project and the encounter with the ground; that is to say a situation very close to reality.

Certainly, all research has not necessarily achieved the ambitious goal of testing hypotheses, but it is certain that we were unable to identify all relevant variables on entrepreneurial processes that positively affect our presented model. In addition, we focus on the research model of entrepreneurial learning at university, but the process begins in elementary school.

\section{References}

Barringer \& Gresock. (2008). Understanding individual factors that contribute to pre-launch planning. Frontiers of Entrepreneurship Research, 28(6).

Boisson, J. P., Arlotto, J., \& Maurin, S. (2008). L'intention entrepreneuriales des étudiants; Grandes Ecoles/ Universités: un faux debat? 5eme Congrés International de l'Académie et l'Entrepreneuriat. 
Carrier, C. (2001). Is It Possible to Teach Creativity, Innovation and Entrepreneurship? Cahier de recherche, UQTR, CR-00-06.

Chandler, G. N., \& Hanks, S. H. (1994). Market attractiveness, Resource-Based Capabilities, Venture Strategy, and Venture Performance. Journal of Business Venturing, 9(4), 331-349. http://dx.doi.org/10.1016/0883-9026(94)90011-6

Drucker, P. F. (1985). Innovation and entrepreneurship. New-York: Harper Row, 1985. http://dx.doi.org/10.1080/07377366.1986.10401060

Evrard, Y., Pras, B., \& Roux, E. (1997). Market. Etudes et recherches en marketing (2nd ed.). Paris.

Fayolle, A. (2000). Exploratory study to assess the effects of entrepreneurship programs on student entrepreneurial behaviours. Journal of Enterprising Culture, 8(2), 169-184.

Fayolle, A., (2000). L'enseignement de l'entrepreneuriat dans le système éducatif supérieur: un regard sur la situation actuelle. Revue Gestion, 3, 77-95.

Honig, M. I. (2006). New directions in education policy implementation: Confronting complexity. Albany: State University of Bew York Press.

Igalens, J., \& Roussel, P. (1998). Méthodes de recherche en gestion des ressources humaines. Paris, Economica.

Jack, S., \& Anderson, A. R. (1999). Entrepreneurship Education within the enterprise culture producing reflective practitioners. International Journal of Entrepreneurial Behaviour and Research, 5(3), 110-125. http://dx.doi.org/10.1108/13552559910284074

Kearney, P. (1999). Enterprising ways to teach and learn. a series of books: - Book 1: "Enterprise Principles". Enterprise Design Associates, North Hobart Tasmania Australia, 1999.

Kearney, P. (2009). Pédagogie et esprit d'entreprendre. Bruxelles : De Boeck.

Kraus, A., White, R. L., \& Hillenbrand. (2006). Multiplicity and optical Excess across the Substellar Boundary in Taurus. The Astrophysical Journal, 649(1). http://dx.doi.org/10.1086/503665

Liao, J., \& Gartner, W. (2008). The Influence of Pre-Venture Planning on New Venture Creation. Journal of Small Business Strategy, 19, 1-32.

Politis \& Diamanto (2005). The process of entrepreneurial Learning: a conceptual framework. Entrepreneurship: Theory and Practice, 399-424. http://dx.doi.org/10.1111/j.1540-6520.2005.00091.x

Schied-Bienfait, N. (1999). Du projet de création comme pratique pédagogique: témoignage autour d'une expérience. $~^{e r}$ Congrès de l'Académie de l'Entrepreneuriat, Lille, 15-16 novembre. 